\title{
EXPOSIÇÃO DE BIOINDICADOR A EXTRATOS AQUOSOS E A FITOTERÁPICO COMERCIAL DE AMBURANA E SUAS IMPLICAÇÕES NA PROLIFERAÇÃO CELULAR
}

\author{
EXPOSICIÓN DEL BIOINDICADOR A EXTRACTOS ACUOSOS Y MEDICINA \\ HERBARIA COMERCIAL DE AMBURANA Y SUS IMPLICACIONES EN LA \\ PROLIFERACIÓN CELULAR
}

\begin{abstract}
BIOINDICATOR EXPOSURE TO WATER EXTRACTS AND COMMERCIAL PHYTOTHERAPIC OF AMBURAN AND ITS IMPLICATIONS IN CELLULAR PROLIFERATION
\end{abstract}

\author{
Matheus Dias Santos ${ }^{1}$; Bárbara Dantas Fontes Soares ${ }^{2}$
}

DOI: https://doi.org/10.31692/978-65-991061-4-9.1-13

\begin{abstract}
RESUMO
A amburana é uma das diversas plantas popularmente utilizadas no Brasil com fins medicinais. A realização de estudos dessas espécies vegetais é de extrema importância para garantir a segurança no uso das mesmas pela população. A utilização de testes como o Allium cepa é uma das formas de se ter uma boa primeira triagem e de alta confiabilidade. $\mathrm{O}$ presente trabalho tem por objetivo avaliar a implicação da exposição a fitoterápico e a diferentes concentrações do extrato aquoso de sementes de Amburana cearensis sobre a proliferação celular em bioindicador. Empregou-se o sistema teste Allium cepa, com 6 tratamentos: T1 - testemunha (água destilada); T2, T3, e T4 - extratos aquosos de $A$. cearensis $\left(10 \mathrm{~g} . \mathrm{L}^{-1}, 20 \mathrm{~g} . \mathrm{L}^{-1}\right.$, e $30 \mathrm{~g} . \mathrm{L}^{-1}$, respectivamente); T5 exposição ao fitoterápico; e T6, exposição à glifosato a $15 \%$, cada tratamento contou com 4 repetições, expondo-se as raízes dos bulbos de cebola aos tratamentos por 24 horas. Procedeu-se preparo e confecção das lâminas que foram observadas ao microscópio óptico com aumento de 40X e posterior análise do Índice Mitótico. Os dados foram analisados por meio do teste Tukey a $5 \%$ de probabilidade. As três diferentes concentrações do extrato aquoso de Amburana cearensis levaram a brusca redução do Índice Mitótico em relação à testemunha, se igualando ao controle positivo (glifosato a 15\%); a exposição ao fitoterápico também levou a redução do índice mitótico. As três diferentes concentrações $\left(10 \mathrm{~g} .{ }^{\mathrm{L}-1}, 20 \mathrm{~g} \cdot{ }^{\mathrm{L}-1} \mathrm{e} 30 \mathrm{~g} .{ }^{\mathrm{L}-1}\right)$ do extrato aquoso de Amburana cearensis bem como o fitoterápico a base de amburana levaram a redução do Índice Mitótico, dessa forma afetando proliferação celular em bioindicador evidenciando efeito citotóxico.
\end{abstract}

Palavras-Chave: Amburana cearensIs, Allium cepa, citotoxicidade, genotoxicidade, planta medicinal

\section{RESUMEN}

Amburana es una de varias plantas utilizadas popularmente en Brasil con fines medicinales. Los estudios de estas especies de plantas son de suma importancia para garantizar la seguridad en su uso por parte de la población. El uso de pruebas como el bioindicador Allium cepa es uno de los primeros y más confiables métodos de detección. El presente trabajo tiene como objetivo evaluar la implicación de la exposición a la medicina a base de hierbas y a diferentes concentraciones de extracto acuoso de semillas de Amburana cearensis en la proliferación celular en bioindicador. Se usó el sistema de prueba Allium cepa como bioindicador y se produjeron 6 tratamientos: T1 - control (agua destilada); T2, T3 y T4: extractos acuosos de A. cearensis (10 g. L-1, 20 g. L-1 y $30 \mathrm{~g}$. L-1, respectivamente); T5 exposición a la medicina a base de hierbas amburana; y T6, 15\% de exposición al glifosato, cada tratamiento tuvo 4 repeticiones, exponiendo las raíces de los bulbos de cebolla a los tratamientos durante 24 horas. Se prepararon y prepararon los portaobjetos, que se observaron bajo el microscopio óptico con un aumento de 40X y posterior análisis del índice mitótico. Los datos se analizaron mediante análisis de varianza y prueba de Tukey con una probabilidad del 5\%. Las tres

\footnotetext{
${ }^{1}$ Agronomia, Universidade Estadual do Sudoeste da Bahia, matheusdiassantos2013@gmail.com

2 Doutorado, Universidade Estadual do Sudoeste da Bahia, barbarafontes@uesb.edu.br
} 
concentraciones diferentes de extracto acuoso de Amburana cearensis (10 gL-1, 20 gL-1 y 30 gL-1) condujeron a una fuerte reducción en el índice mitótico en comparación con el control, igualando el control positivo (15\% de glifosato). mientras que la medicina herbal basada en amburano produjo una reducción en el índice mitótico. Por lo tanto, los tratamientos evaluados afectaron la proliferación celular en A. cepa que mostró un efecto citotóxico.

Palabras Clave: Amburana cearensis, Allium cepa, citotoxicidad, genotoxicidad, plantas medicinales

\begin{abstract}
Amburana is one of several plants popularly used in Brazil for medicinal purposes. Studies of these plant species are of utmost importance to ensure safety in their use by the population. The use of tests such as the Allium cepa bioindicator is one of the first and most reliable screening methods. The present work aims to evaluate the implication of exposure to herbal medicine and different concentrations of aqueous extract of Amburana cearensis seeds on cell proliferation in bioindicator. Allium cepa test system was used as bioindicator and 6 treatments were produced: T1 - control (distilled water); T2, T3, and T4 - aqueous extracts of A. cearensis (10g.L-1, 20g.L-1, and 30g.L-1, respectively); T5 exposure to amburana herbal medicine; and T6, 15\% glyphosate exposure, each treatment had 4 repetitions, exposing the roots of the onion bulbs to the treatments for 24 hours. The slides were prepared and made, which were observed under the optical microscope with 40X magnification and subsequent analysis of the Mitotic Index. Data were analyzed by analysis of variance and Tukey test at 5\% probability. The three different concentrations of Amburana cearensis aqueous extract (10 gL-1, $20 \mathrm{gL}-1$ and $30 \mathrm{gL}-1)$ led to a sharp reduction in Mitotic Index in relation to the control, equaling the positive control (15\% glyphosate). while amburan-based herbal medicine produced a reduction in the mitotic index. Thus, the treatments tested affected cell proliferation in A. cepa showing cytotoxic effect.
\end{abstract}

Keywords: Amburana cearensis, Allium cepa, cytotoxicity, genotoxicity, medicinal plant

\title{
INTRODUÇÃO
}

As plantas medicinais são uma importante fonte de produtos naturais biologicamente ativos dos quais, muitos, são utilizados na produção de um grande número de fármacos, sendo que as preparações fitoterápicas correspondem a até $80 \%$ dos medicamentos utilizados em países em desenvolvimento por motivos de ordem médica, social, cultural, econômica ou filosófica, sendo, algumas vezes, o único medicamento disponível à população. No entanto, apesar do amplo uso, ainda são poucos os estudos para avaliar a eficácia terapêutica e a toxicidade potencial dessas preparações fitoterápicas (BELCAVELLO, et al., 2012; DIAS, et al., 2014; PERON, et al., 2008).

A amburana, Amburana cearensis, também conhecida por ambaurana, baru, cumarudo-ceará, cumaru-das-caatingas, imburana-de-cheiro, louro-ingá, umburana, cerejeira-rajada e outros nomes populares é uma dessas plantas. Utilizada para a terapia de algumas doenças como dores abdominais, reumatismo, tosse, bronquite, asma, como analgésico e espasmolítico (ALVES, ALVES \& PEREIRA, 2016; MELLO, 2013) possui alguns estudos que verificaram ação tóxica, tendo sido recomendados novos estudos a fim de se garantir a segurança no uso da mesma (SANTOS \& SOARES, 2018; MELLO, et al., 2013).

Dentre os meios para avaliação de produtos naturais provindos de plantas medicinais, 
tem-se os sistemas testes vegetais que funcionam como estudos preliminares dos efeitos de extratos vegetais permitindo a detecção de possíveis efeitos tóxicos, servindo como uma primeira triagem. O sistema teste Allium cepa é um desses testes (DIAS, et al., 2014; VERRI, MOURA \& MOURA, 2017). Santos e Soares (2018) citam que os efeitos produzidos por substâncias presentes nos extratos vegetais e seus derivados podem ser avaliados mediante diversos bioensiaios citogenéticos que apresentam resultados com considerável sensibilidade e confiabilidade, onde, se o agente gerar alterações no ciclo celular, bem como danos ao DNA acredita-se que há potencial citotóxico, genotóxico e mutangênico para diferentes tipos de células, sejam elas vegetais, animais e microbianas.

Assim, o presente trabalho tem por objetivo avaliar a implicação da exposição a fitoterápico e a diferentes concentrações do extrato aquoso de sementes de Amburana cearensis sobre proliferação celular em bioindicador

\section{FUNDAMENTAÇÃO TEÓRICA}

A amburana é considerada uma planta nativa da Caatinga nordestina e possui ampla distribuição na América do Sul, com registros de sua ocorrência na Argentina, Bolívia, Paraguai e Peru. Árvore pertencente à família Fabaceae apresenta caule ereto, que chega a atingir de 10 a 12 metros de altura. Sua madeira é utilizada na movelaria e suas cascas e sementes tem apreciáveis propriedades terapêuticas na medicina popular. Apresenta atividade anti-inflamatória, analgésica, antiespasmódica e broncodilatadora, sendo utilizada no tratamento de doenças como gripes, resfriados, asmas, bronquite, alívio sintomático de dorde-dente, dor de barriga, reumatismo, entre outras (ALVES, ALVES \& PEREIRA, 2016; MELLO, 2013).

Vários compostos já foram isolados e identificados da Amburana cearensis e incluem ácido protocatecuico, cumarinas, flavonoides, glicosídeos fenólicos, dentre outros (ALVES, ALVES \& PEREIRA, 2016). Hoje, sabe-se que plantas medicinais, da mesma forma que os medicamentos sintéticos, possuem grupos de compostos farmacologicamente ativos que atuam no organismo (PERON, et al., 2008). No Brasil, essas plantas têm seu uso promovido pelo difícil acesso da população à assistência médica e farmacêutica, pelo custo dos medicamentos industrializados e pela tendência dos consumidores a utilizarem produtos de origem natural. No entanto, de forma equivocada, muitas vezes as plantas medicinais são utilizadas de forma indiscriminada, sem preocupação acerca de efeitos colaterais e/ou tóxicos (MACEDO et al., 2014).

Assim, o emprego dessas plantas exige seu conhecimento, para avaliação de suas 
potencialidades terapêuticas, tóxicas e para formulação de uma estratégia de uso adequada (PERON et al., 2008), estudos como esses servem para estabelecer a atividade, esclarecer mecanismos de ação, ou mesmo identificar componentes ativos e investigar os possíveis efeitos tóxicos de diferentes espécies vegetais dando segurança no uso, bem como servindo, também, para interesses farmacológicos (BELCAVELLO et al., 2012).

Dentre as formas de avaliar os efeitos de substâncias presentes nos produtos naturais, principalmente extratos vegetais e seus derivados, tem-se diversos bioensaios que apresentam considerável sensibilidade e confiabilidade dos resultados. O teste de Allium cepa destaca-se entre esses testes, sendo muito utilizado no monitoramento de genotoxicidade, citotoxicidade e toxicidade de produtos naturais devido sua alta sensibilidade e correlações com outros testes. Ele é considerado uma importante ferramenta e biomarcador no monitoramento da toxicidade de extratos e infusões de plantas medicinais e os resultados têm indicado como principais efeitos o aumento ou diminuição da proliferação celular, bem como estabelecer que muitas plantas podem apresentar efeito mutangênico e antimutangênico (VERRI, MOURA \& MOURA, 2017).

Esse bioensio é considerado uma das abordagens mais eficientes e é rotineiramente usado para determinar os efeitos tóxicos de compostos químicos no ambiente; foi validado por muitos pesquisadores que realizaram esse teste de forma conjunta à testes em animais in vivo e obtiveram resultados similares, o que proporciona que este teste traga informações valiosas para a saúde humana. Associa-se como vantagens a esse teste, sua alta sensibilidade e relação custo-benefício, possibilidade de medição de parâmetros macroscópicos e microscópicos e uma boa correlação com mamíferos (DIAS et al., 2014).

A utilização de bioensaios biológicos vegetais para o monitoramento da bioatividade de extrato, frações e compostos isolados de plantas têm sido incorporados frequentemente à identificação e monitoramento de substâncias potencialmente tóxicas. A citotoxicidade de uma substância pode ser avaliada por meio da verificação de alterações no processo de divisão celular sobre o organismo-teste e pela incidência de mutações cromossômicas (SILVA et al., 2013).

Muitas plantas são úteis de forma medicinal, no entanto é necessário realizar avaliações de toxicidade com a avaliação do índice mitótico, para a verificação do desenvolvimento normal das células do organismo e assim correlacionar com a seguridade no uso das mesmas pela população, uma vez que a mesma, por vezes, faz uso exagerado de determinada planta devido à crença popular de que não causa mal algum, pelo simples fato desta ser de origem natural (PORTIS et al., 2016). 
Pesquisas realizadas por Mello et al., (2013) verificaram que o extrato aquoso da amburana comprometeu o índice mitótico e provocou gradativo efeito genotóxico em meristemas radiculares de cebola; Santos e Soares (2018) verificaram efeito citotóxico pela diminuição do índice mitótico e ocorrência de apoptose das células meristemáticas de alface, ambos os trabalhos observando o efeito do extrato de amburana sobre os bioindicadores vegetais ao longo do aumento do tempo de exposição ao extrato aquoso das sementes dessa planta medicinal. A espécie também causou prejuízos na germinação, no crescimento radicular e no desenvolvimento de outras diferentes espécies vegetais (MANO, 2006; SILVA et al., 2006; FELIX, ONO, ARAÚJO, 2010).

Dessa forma, visto que a população faz amplo uso de fitomedicamentos e que ainda se carece de estudos para avaliar a sua toxicidade potencial, os quais podem apresentar vários agravos à saúde, investigações acerca dos efeitos produzidos por vegetais utilizados na medicina popular são de extrema importância (BELCAVELLO, et al., 2012; SANTOS \& SOARES, 2018).

\section{METODOLOGIA}

Este trabalho é de natureza quantitativa, do tipo experimental e foi conduzido no Laboratório de Citogenética da Universidade Estadual do Sudoeste da Bahia (UESB) Campus de Vitória da Conquista/BA.

As sementes de Amburana cearensis foram obtidas por coleta em árvores matrizes localizadas na Fazenda Santo Antônio das Flores, situada no Município de Anagé, BA; o fitoterápico medicinal foi adquirido em compra via internet em site de produtos naturais; e o glifosato, utilizando o produto comercial Roundup, cuja concentração nesse produto é de $36 \%$ $(\mathrm{m} / \mathrm{v})$, tendo sido a concentração da solução utilizada como tratamento ajustada para $15 \%$ após diluição em água destilada no momento do uso.

rcado local; retirou-se as cascas externas e que se encontravam secas e, com objeto cortante, removeu-se o excesso de raízes mortas a fim de facilitar o processo de enraizamento. Em seguida os bulbos foram submetidos a lavagem em água corrente e após remoção do excesso de umidade foram colocadas para enraizar. Para isso, inseriu-se 3 hastes de madeira nas laterais de cada bulbo de cebola de forma a mantê-los equilibrados sobre copos descartáveis e com a parte basal em contato com a água destilada contida nos mesmos. Após emissão das raízes, preparou-se, então, para exposição aos tratamentos.

As três diferentes concentrações do extrato aquoso de A. cearensis foram preparadas por meio de maceração mecânica a seco das sementes e trituração em liquidificador para 
melhor refinamento das mesmas, obtido o macerado, realizou-se pesagem e transferência de 2,5g, 5,0g, e, 7,5g de macerado para 3 respectivos béqueres contendo, cada um, $250 \mathrm{~mL}$ de água destilada fervente, mantendo sobre fonte de calor equivalente à fogo baixo por 10 minutos; após homogeneização, aguardou-se esfriamento em temperatura ambiente e, então, as soluções foram coados em papel filtro. Obteve-se os extratos nas concentrações finais de 10g. $\mathrm{L}^{-1}$ (usual), 20g.L $\mathrm{L}^{-1}$, e 30g.L $\mathrm{L}^{-1}$, respectivamente (LORENZI e MATOS, 2002; RECEITA NATURAL, 2019).

O experimento, configurado em delineamento inteiramente casualizado (DIC), contou com 6 tratamentos e cada tratamento com 4 repetições ( 4 bulbos), totalizado 24 parcelas (24 bulbos), expondo-se as raízes aos tratamentos por período de 24 horas.

O tratamento 1 (T1) - testemunha ou controle negativo, consistiu na exposição das raízes apenas à água destilada; o Tratamento 2 (T2) na exposição das raízes ao extrato aquoso de A. cearensis na concentração de $10 \mathrm{~g} . \mathrm{L}^{-1}$; o Tratamento 3 (T3) na exposição ao extrato na concentração de 20g.L -1 $^{-1}$ o Tratamento 4 (T4) na exposição ao extrato aquoso de A. cearensis na concentração de $30 \mathrm{~g} . \mathrm{L}^{-1}$; o Tratamento 5 (T5) consistiu na exposição das raízes ao fitoterápico; e, o Tratamento 6 (T6) - controle positivo - na exposição ao glifosato na concentração de $15 \%$. Para realização dessa exposição a água destilada dos recipientes em que os bulbos se encontravam para enraizar foi substituída pelos respectivos tratamentos, mantendo-se as raízes imersas. As soluções foram preparadas no dia de sua utilização.

Findado o tempo de exposição, as raízes foram coletadas e passaram por três lavagens de 10 minutos em água destilada e fixadas em carnoy (3 metanol: 1 ácido acético) realizandose 3 trocas em intervalos de 15 minutos, após terceira troca, manteve-se o material na solução que foi colocado em ambiente com refrigeração $\left(-6^{\circ} \mathrm{C}\right)$ por, no mínimo, 24 horas e assim permanecendo até momento de uso.

Para o preparo das lâminas, as radículas foram retiradas do carnoy e lavadas 3 vezes em água destilada com intervalos de 5 minutos. Em seguida, foram submetidas à hidrólise em $\mathrm{HCl} 1 \mathrm{~N}$ a $60^{\circ} \mathrm{C}$ por 8 minutos. A hidrólise foi interrompida em água destilada gelada e os meristemas foram transferidos para reativo de Schift para coloração. Cada lâmina foi confeccionada gotejando-se ácido acético $45 \%$ sobre a radícula com posterior excisão da região meristemática; após obter três meristemas radiculares por repetição, o material foi coberto com lamínula, realizando-se batidas sequenciais sobre a mesma e, posteriormente, envolveu-se o conjunto lâmina-lamínula com papel toalha para aplicação de pressão com o polegar a fim de favorecer o espalhamento das células e retirada do excesso de ácido acético (GUERRA e SOUZA, 2003, modificado). 
As lâminas foram observadas com auxílio de microscópio óptico Nova Optical Systems, com objetiva de 40X. Para realização do cálculo do Índice Mitótico, contou-se o número de células em cada fase da divisão mitótica (intérfase, prófase, metáfase, anáfase e telófase) e dividiu-se pelo número total de células analisadas e o resultado foi multiplicado por 100. Analisou-se 1 lâmina por repetição, observando-se 2000 células em cada uma, dessa forma totalizando 8000 células por tratamento.

As análises estatísticas foram realizadas por meio do teste de Cochran para avaliação da homogeneidade e teste de Lilliefors para avaliação da normalidade, os dados foram transformados e submetidos a análise de variância (teste F) e as médias obtidas dos diferentes tratamentos comparadas pelo teste Tukey a 5\% de probabilidade, utilizando-se o programa SAEG (Sistema de Análises Estatísticas e Genétias), versão 9.1, Ribeiro e Junior (2001).

\section{RESULTADOS E DISCUSSÃO}

A Tabela 1 mostra a análise de variância apresentando os quadrados médios daquelas características analisadas cujos valores foram significativos, dessa forma, as fases de metáfase, prófase, anáfase e intérfase apresentam diferenças significativas em função dos tratamentos, bem como o Índice Mitótico.

Tabela 1: Análise de variância e coeficiente de variação das características prófase (PRÓF), metáfase (MET), anáfase (ANÁF), interfase (INTER) e Índice Mitótico (IM) dos meristemas radiculares de cebola submetidas aos tratamentos Testemunha/controle negativo T1 (água destilada), T2, T3, T4 (T2 (extratos aquosos de amburana nas concentrações de $10 \mathrm{~g} . \mathrm{L}^{-1}, 20 \mathrm{~g} . \mathrm{L}^{-1}, 30 \mathrm{~g} . \mathrm{L}^{-1}$, respectivamente), T5 (fitoterápico a base de amburana) e Controle positivo T6 (glifosato a 15\%). Vitória da Conquista, BA. 2019.

\begin{tabular}{lcccccc}
\hline \multirow{2}{*}{ FV } & \multirow{2}{*}{ GL } & \multicolumn{5}{c}{ QUADRADOS MÉDIOS } \\
\cline { 3 - 7 } & & PRÓF & MET & ANÁF & INTER & IM \\
\hline TRATAMENTO & 5 & 85,4426 & 12,2370 & 1,4176 & 0,2177 & 4,8550 \\
\hline RESÍDUO & 18 & 0,8724 & 0,1510 & 0,2770 & 0,2924 & 0,3559 \\
\hline CV\% & & 20,44 & 19,29 & 91,21 & 0,26 & 12,38 \\
\hline
\end{tabular}

Fonte: Própria (2019).

A Tabela 2 mostra o comportamento das médias dessas características analisadas nos meristemas radiculares de cebola em relação aos tratamentos a que foram expostas. Em virtude da necessidade de transformação dos dados, as médias originais se encontram entre parênteses. Analisando os dados de metáfase, nota-se que o controle negativo, testemunha, em que as raízes foram submetidas apenas a água destilada, foi o que apresentou maior média de células em metáfase, seguida do tratamento em que os meristemas radiculares foram expostos ao fitoterápico, não havendo diferença significativa entre os demais tratamentos que obtiveram as menores médias de células na fase de metáfase.

Comportamento semelhante ocorre para a fase de prófase, diferindo apenas pelo fato 
de que o tratamento em que as raízes foram expostas ao extrato aquoso na concentração de $30 \mathrm{~g} . \mathrm{L}^{-1}$ obteve média de células em fase de prófase superior ao controle positivo $(15 \%$ de glifosato), no entanto, ambos não diferem estatisticamente das concentrações de 10 e $20 \mathrm{~g} . \mathrm{L}^{-1}$.

Tabela 2: Número de células em prófase, metáfase, anáfase, interfase e Índice Mitótico (IM) dos meristemas radiculares de cebola submetidas aos tratamentos Testemunha/controle negativo T1 (água destilada), T2, T3, T4

(T2 (extratos aquosos de amburana nas concentrações de 10g.L ${ }^{-1}, 20 \mathrm{~g} . \mathrm{L}^{-1}, 30 \mathrm{~g} . \mathrm{L}^{-1}$, respectivamente), T5

(fitoterápico a base de amburana) e Controle positivo T6 (glifosato a 15\%). Vitória da Conquista, BA. 2019.

\begin{tabular}{|c|c|c|c|c|c|}
\hline TRATAMENTO & PRÓFASE & METÁFASE & ANÁFASE & INTERFASE & IM (\%) \\
\hline Testemunha & $\begin{array}{c}11,562 \mathrm{a}^{*} \\
(134,1)\end{array}$ & $\begin{array}{c}4,759 \mathrm{a}^{*} \\
(22,5)\end{array}$ & $\begin{array}{c}-0,257 \mathrm{~b}^{* *} \\
(8,80)\end{array}$ & $\begin{array}{l}6,551 \mathrm{c}^{*} \\
(1812,5)\end{array}$ & $\begin{array}{c}3,237 \mathrm{a}^{*} \\
(10,04)\end{array}$ \\
\hline Extrato 10g.L $\mathrm{L}^{-1}$ & $\begin{array}{c}0,974 \mathrm{~cd}^{*} \\
(0,53)\end{array}$ & $\begin{array}{c}0,825 \mathrm{c}^{*} \\
(0,22)\end{array}$ & $\begin{array}{c}0,909 \mathrm{ab}^{* *} \\
(0,22)\end{array}$ & $\begin{array}{l}6,724 a^{*} \\
(1999,6)\end{array}$ & $\begin{array}{c}0,739 \mathrm{c}^{*} \\
(0,05)\end{array}$ \\
\hline Extrato 20g. $\mathrm{L}^{-1}$ & $\begin{array}{c}2,048 \mathrm{~cd}^{*} \\
(4,90)\end{array}$ & $\begin{array}{c}0,807 \mathrm{c}^{*} \\
(0,18)\end{array}$ & $\begin{array}{c}1,000 \mathrm{a}^{* *} \\
(0,00)\end{array}$ & $\begin{array}{l}6,721 \mathrm{a}^{*} \\
(1997,6)\end{array}$ & $\begin{array}{c}0,855 \mathrm{c}^{*} \\
(0,25)\end{array}$ \\
\hline Extrato 30g.L $\mathrm{L}^{-1}$ & $\begin{array}{c}2,966 \mathrm{c}^{*} \\
(9,64)\end{array}$ & $\begin{array}{c}1,327 \mathrm{c}^{*} \\
(1,41)\end{array}$ & $\begin{array}{c}0,930 \mathrm{a}^{* *} \\
(0,19)\end{array}$ & $\begin{array}{l}6,716 a^{*} \\
(1989,9)\end{array}$ & $\begin{array}{c}1,013 \mathrm{c}^{*} \\
(0,56)\end{array}$ \\
\hline Fitoterápico & $\begin{array}{c}9,166 \mathrm{~b}^{*} \\
(83,91)\end{array}$ & $\begin{array}{c}3,660 \mathrm{~b}^{*} \\
(13,1)\end{array}$ & $\begin{array}{c}-0,119 \mathrm{ab}^{* *} \\
(9,38)\end{array}$ & $\begin{array}{l}6,618 b^{*} \\
(1871,4)\end{array}$ & $\begin{array}{c}2,594 b^{*} \\
(6,26)\end{array}$ \\
\hline Glifosato $15 \%$ & $\begin{array}{c}0,707 \mathrm{~d}^{*} \\
(0,00)\end{array}$ & $\begin{array}{c}0,707 \mathrm{c}^{*} \\
(0,00)\end{array}$ & $\begin{array}{c}1,000 \mathrm{a} * * \\
(0,00)\end{array}$ & $\begin{array}{c}6,725 \mathrm{a}^{*} \\
(2000)\end{array}$ & $\begin{array}{c}0,707 \mathrm{c}^{*} \\
(0,00)\end{array}$ \\
\hline
\end{tabular}

Transformação: $* * \operatorname{Cos}(\mathrm{x}) ; * \sqrt{x+0,5}$. Médias seguidas de mesma letra na coluna não diferem entre si pelo teste Tukey $(\mathrm{P}>0,05)$. Fonte: Própria (2019).

Em relação a fase de anáfase, o grupo testemunha obteve maior média de células nessa fase em relação ao controle positivo e aos tratamentos em que as raízes foram expostas às concentrações de 20 e $30 \mathrm{~g} . \mathrm{L}^{-1}$, a concentração de $10 \mathrm{~g} \cdot \mathrm{L}^{-1}$ e a exposição ao fitoterápico levou a médias que não diferem entre os tratamentos.

Quanto à fase de interfase, as menores médias foram obtidas para o tratamento testemunha, seguido do tratamento em que se expôs ao fitoterápico, sendo as maiores médias obtidas para os tratamentos em que se expôs às diferentes concentrações do extrato aquoso de amburana e ao controle positivo ( $15 \%$ de glifosato), sendo as médias desses tratamentos estatisticamente iguais. Esse resultado está diretamente relacionado ao obtido na análise do índice mitótico, quanto maior o número de células em interfase, menor será o índice mitótico e, por isso obteve-se, então, maior índice mitótico no tratamento testemunha, seguido do tratamento com exposição ao fitoterápico e, por fim, os tratamentos que consistiram na exposição às três diferentes concentrações do extrato aquoso de amburana e ao glifosato a $15 \%$, tratamentos estes que não diferiram entre si.

Tais resultados permitem verificar que a exposição das raízes dos bulbos de cebola por 24 horas a qualquer uma das três concentrações do extrato aquoso de sementes de amburana levou a brusca queda no índice mitótico em relação ao tratamento testemunha, evidenciando ação citotóxica uma vez que afetou negativamente a divisão celular equiparando-se ao tratamento controle positivo. Nota-se que a exposição ao fitoterápico também levou a redução 
do índice mitótico, de uma maneira não tão severa quanto os extratos, no entanto, a concentração de amburana no fitoterápico comercial não é informada.

Redução do índice mitótico também foi verificada por Dias et al, (2014) ao analisar o efeito genotóxico e antiproliferativo de Mikania cordifolia sobre o ciclo celular de Allium сера relatando atividade antiproliferativa associando essa redução a grande quantidade, dentre outros compostos, de cumarina (1,2-benzenopirona) e flavonoides presentes no gênero Mikania e também relatados como presentes na amburana (ALVES, ALVES \& PEREIRA, 2016).

Silva et al, (2013) utilizando sistema teste Allium cepa como bioindicador de citotoxicidade de substâncias usadas na conserva, obteve efeito citotóxico caracterizado pela redução do índice mitótico apenas nas maiores concentrações por eles empregues. Já Macedo et al, (2014) realizando estudo da citogenotoxicidade de extrato de quiabo também pelo teste Allium cepa, não obteve nenhuma alteração que pudesse ser indicativo de toxicidade do quiabo tanto em baixas ou em altas concentrações o que considerou como seguridade para o uso dessa planta pela população.

Santos et al, (2018) relatam que os efeitos de chás, infusões ou soluções extrativas de plantas medicinais devem ser monitoradas utilizando ensaios toxicológicos, destacando-se os genotóxicos e/ou mutengênicos, objetivando orientar os usuários sobre possíveis consequências para a saúde.

Aspecto geral das células meristemáticas de cebola em virtude dos tratamentos a que foram submetidas pode ser verificado na Figura 1. Conforme apresentado em dados numéricos na Tabela 2, pode-se observar maior intensidade de células em divisão na Figura 1A, que foi submetida apenas à água destilada. Ao observar a Figura 1B, nota-se que praticamente cessa a divisão celular, bem como ocorre na Figura 1D, nessa nota-se ainda que além de afetar o processo de divisão celular a morfologia das mesmas também foi prejudicada, onde as células apresentam núcleos mais deformados, em decorrência do efeito do tratamento a base de glifosato. Observando a Figura 1C, verifica-se novamente processo de divisão celular, esse tratamento corresponde ao tratamento em que as raízes foram expostas ao fitoterápico, onde a redução do índice mitótico não foi tão drástica quanto em comparação com o que ocorreu em decorrência dos extratos e do controle positivo.

Experimento realizado por Santos et al, (2018) avaliando a ação citotóxica, genotóxica e mutangênica do extrato de Morinda citrifolia em diferentes concentrações sobre o teste Allium cepa, utilizando água mineral como controle negativo e paracetamol como controle positivo, observaram que todas as concentrações do extrato testado levaram a toxicidade sobre 
o sistema teste Allium cepa evidenciado pela inibição dos meristemas das raízes diminuição significativa do número de mitoses observadas nos tratamentos à medida que houve aumento na concentração do extrato da planta.

Figura 1: Aspecto geral das células meristemáticas de cebola submetidas aos tratamentos Testemunha/controle negativo T1 (água destilada) Figura 1A; T2, T3, T4 (aos extratos aquosos de amburana nas concentrações de 10g.L $\mathrm{L}^{-1}, 20 \mathrm{~g} . \mathrm{L}^{-1}, 30 \mathrm{~g} . \mathrm{L}^{-1}$, respectivamente), sendo representados pela Figura 1B; T5 (fitoterápico a base de amburana) Figura 1C; e Controle positivo T6 (glifosato a 15\%) Figura 1D. Vitória da Conquista, BA. 2019.
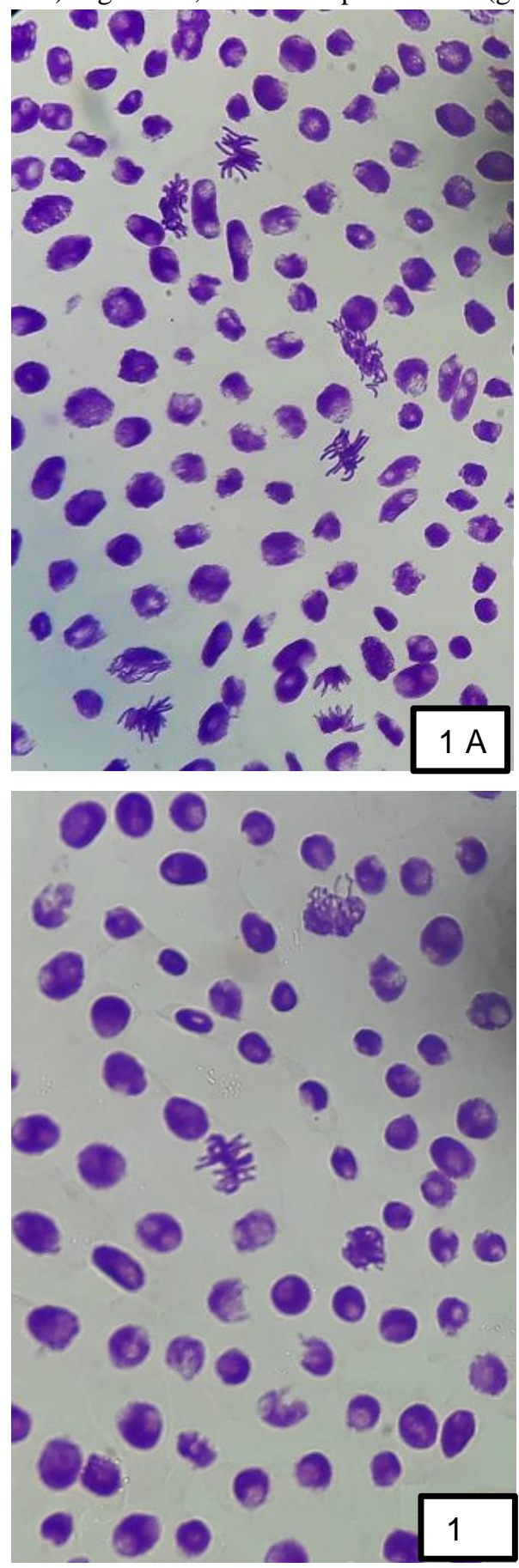
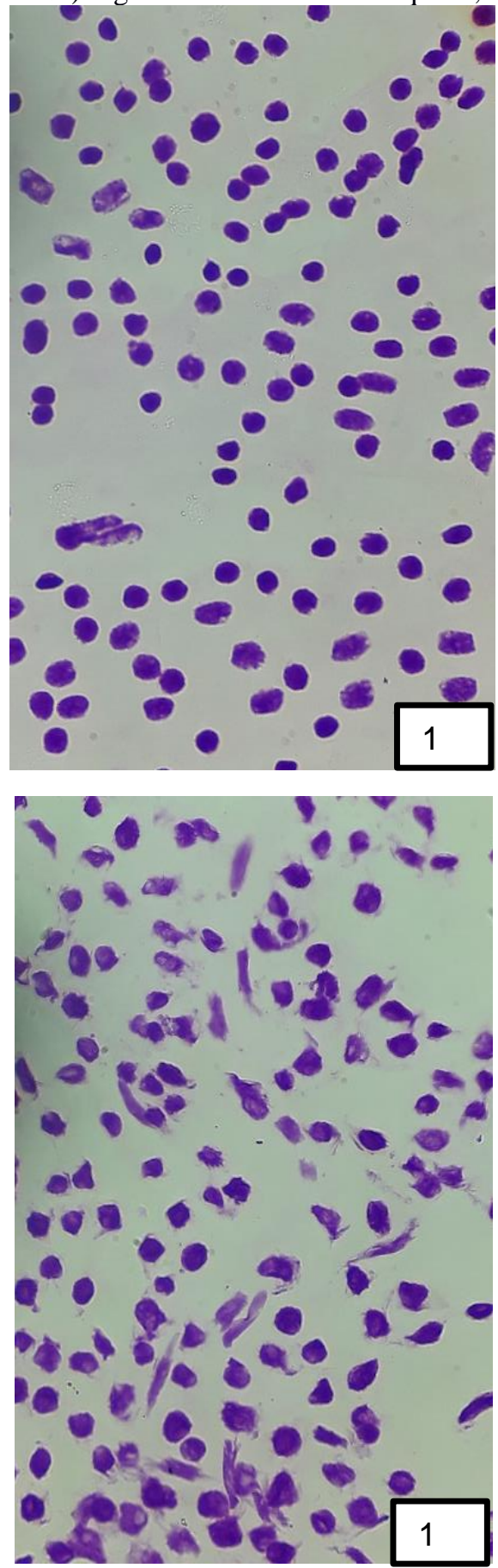

Coelho et al, (2013), avaliando compostos fenólicos e potencial genotóxico e antiproliferativo do extrato de erva-do-brejo (Echinodorus longiscapus Arech) em duas 
diferentes concentrações comparando com controle negativo - água - e controle positivo glifosato a $15 \%$ - mostraram que a espécie possui potencial antiproliferativo com o aumento da concentração e consequente aumento nos constituintes fitoquímicos, o que foi evidenciado pela redução do índice mitótico.

Em estudos realizados por Mello et al, (2014) utilizando a concentração de 23,4 g.L -1 $^{-1}$ do extrato aquoso de sementes de amburana levou a decréscimo do índice mitótico a medida que se aumentou o tempo de exposição ao extrato e relataram aumento gradativo de genotoxicidade. Já Santos e Soares (2018) utilizando a concentração de 20,0 g.L.-1 do extrato aquoso verificaram ação citotóxica tanto pela redução do índice mitótico quanto pelo aumento da porcentagem de apoptose também em relação ao aumento do tempo de exposição, relatando serem necessários maiores cuidados, uma vez que os resultados obtidos para a presença de substancias tóxicas não necessariamente desqualificam o seu uso medicinal, mas vem mostrar a necessidade de estudos para determinar dosagens, avaliar efeitos cumulativos ou dizer se são impróprias para o consumo.

\section{CONCLUSÕES}

As três diferentes concentrações (10 g. ${ }^{\mathrm{L}-1}, 20 \mathrm{~g} .^{\mathrm{L}-1}$ e $\left.30 \mathrm{~g} .^{\mathrm{L}-1}\right)$ do extrato aquoso de Amburana cearensis bem como o fitoterápico a base de amburana levaram a redução do Índice Mitótico, dessa forma afetando proliferação celular em bioindicador evidenciando efeito citotóxico.

\section{REFERÊNCIAS}

ALVES, H. B.; ALVES, H. B.; PEREIRA, F. R. A. Aspectos químicos e farmacológicos do cumaru (Amburna cearensis): um fitoterápico próprio do semiárido. I congresso Internacional da Diversidade do Semiárido. 2016.

BECAVELLO, L.; CUNHA, M.R.H.; ANDRADE, M.A.; BATITUCCI, M.C. Citotoxidade e danos ao DNA induzidos pelo extrato de Zornia diphylla, uma planta medicinal. Natureza online, 2012.

COELHO, A. P. D.; FRESCURA, V. D.S.; MAMBRI, A. P.; BOLIGON, A. A.; TEDESCO, S. B. Avaliação dos compostos fenólicos e potencial genotóxico e antiproliferativo do extrato de Echinodorus longiscapus Arech. Enciclopédia Biosfera, Centro Científico conhecer Goiânia, v.9, n.16, p.2698. 2013.

DIAS, M.G.; CANTO-DOROW, T.S.; COELHO, A.P.D.; TEDESCO, S.B. Efeito genotóxico e antiproliferativo de Mikania cordifolia (L. F.) Willd. (Asteraceae) sobre o ciclo celular de Allium cepa (L.). Revista Brasileira de Plantas Medicinais, v.16, n.2, p.202-208, 2014. 
FELIX, R. A. Z.; ONO, E. O.; ARAÚJO, F. P. Efeitos alelopáticos de extrato de Amburana cearensis na germinação de sementes de rabanete. Cultivando o Saber. Cascavel, v.3, p.18-31, 2010.

GUERRA, M.; SOUZA, M.J. Como observar cromossomos: um guia de técnica em citogenética vegetal, animal e humana. São Paulo: Funpec. 2003, 131p.

LORENZI H.; MATOS F.J.A. Plantas medicinais no Brasil: nativas e exóticas. Nova Odessa: Plantarum. 2002, 512p.

MACEDO, J.F.M.; SILVA, M.S.; BATISTA, N.J.C.; UCHOA, V.T.; ALVES, W.S. Estudo da genotoxicidade do extrato d Abelmoshus esculentus (quiabo) pelo teste Allium cepa. Revista Saúde em Foco, Teresina, v.1, art.2, p.15-28, jan./jul. 2014.

MANO, A. R. O. 2006. Efeito alelopático do extrato aquoso de sementes de cumaru (Amburana cearensis S.) sobre germinação de sementes, desenvolvimento e crescimento de plântulas de alface, picão-preto e carrapicho. Dissertação Mestrado em Agronomia, Centro de Ciências Agrárias, Universidade Federal do Ceará, Fortaleza, Brasil. 102 p.

MELLO, V.S.; VIEIRA, A.; MIRANDA, D.P.; TEIXEIRA, A.D.; KARSBURG, I.V. Genotoxicidade da infusão de Amburana cearensis (Allemão) A. C. Smith. Pelo sistema teste Allium cepa.In: I Seminário de Biodiversidade e agroecossistemas Amazônicos, Alta Floresta - MT. Genética e melhoramento, 2013.

PERON, A. P.; MARCOS, M. C.; VICENTINI, V. E. P. Avaliação do potencial citotóxico dos chás de Camellia sinensis L. e Cassia angustifólia vahl em sistema teste vegetal. Arq. Ciênc. Saúde Unipar, Umurama, v.12, n.1, p.51-54, jan./abr. 2008.

PORTIS, I. G.; FIGUEIREDO, F. R. G.; PENA, R. V.; HANUSCH, A. L.; SOUZA, L. P. de.; MACHADO, R. C.; SILVA, C. C. de.; CRUZ, A. D. de. Bioensaio citogenético para a caracterização da mutangenicidade e citotoxicidade da espécie Choclhospermium regium.

Refacer, v.5, n.1, 2016.

RECEITA NATURAL. Chá de emburana. Disponível em: $<<$ https://natural.enteernauta.com.br/cha-de-emburana $>>$.

SANTOS, M. D.; SOARES, B. F. Atividade Antimitótica e apoptótica provocadas por extrato de umburana em sistema teste vegetal. Anais de Evento. Artigo Completo. III Congresso Internacional das Ciências Agrárias. Jõao Pessoa, Paraíba. 08-13 dez. 2018.

SANTOS, I. M. C. dos.; MELO, H. M. de.; CARNEIRO, J. K. R.; OLIVEIRA, M. A. S. Avaliação citotóxica, genotóxica e mutangênica do extrato de Morinda citrifolia em diferentes concentrações sobre o teste Allium cepa. Revista de Ciências Médicas e Biológicas, Salvador, v.17, n.1, p. 40-45, jan./abr.2018.

SILVA, B.M. NISHIMUTA, H.A.; SANTOA, E.T.B.; COSTA, D.N.G.; ROSSI, A.A.B. Sistema teste Allium cepa como bioindicador de citotoxicidade de substâncias usadas na conserva de Olea europea L. In: I Seminário de Biodiversidade e Agroecossistemas Amazônicos, Alta Floresta - MT, 23 e 24 set. 2013. 
SILVA, W. A.; NOBRE, A. P.; LEITES, A. P.; SILVA, M. S. C.; LUCAS, R. C.; RODRIGUES, O. G. Efeito alelopático de extrato aquoso de Amburana cearensis A. Smith na germinação e crescimento de sementes de sorgo (Sorghum bicolor L.). Agropecuária científica no Semi-árido 2(1): 48-54, 2006.

VERRI, A. M.; MOURA, A. A.; MOURA, V. M. Testes citogenéticos na avaliação da genotoxicidade de produtos naturais provindos de plantas medicinais. Revista UNINGÁ Review, v.30, n.1, p.55-61, 2017. 